\title{
Where does the black population of South Africa stand on the nutrition transition?
}

\author{
Lesley T Bourne ${ }^{1, *}$, Estelle V Lambert ${ }^{2}$ and Krisela Steyn ${ }^{3}$
}

'Health and Development Research Group, Medical Research Council (MRC), PO Box 19070, Tygerberg 7505, South Africa: ${ }^{2}$ MRC/UCT Exercise Science and Sports Medicine Research Unit, University of Cape Town, Sports Science Institute of South Africa: ${ }^{3}$ Chronic Diseases of Lifestyle Unit, Medical Research Council, Tygerberg, South Africa

\begin{abstract}
Objective: To review data on selected risk factors related to the emergence of noncommunicable diseases (NCDs) in the black population of South Africa.

Methods: Data from existing literature on South African blacks were reviewed with an emphasis placed on changes in diet and the emergence of obesity and related NCDs. Design: Review and analysis of secondary data over time relating to diet, physical activity and obesity and relevant to nutrition-related NCDs.

Settings: Urban, peri-urban and rural areas of South Africa. National prevalence data are also included.

Subjects: Black adults over the age of 15 years were examined.

Results: Shifts in dietary intake, to a less prudent pattern, are occurring with apparent increasing momentum, particularly among blacks, who constitute three-quarters of the population. Data have shown that among urban blacks, fat intakes have increased from $16.4 \%$ to $26.2 \%$ of total energy (a relative increase of $59.7 \%$ ), while carbohydrate intakes have decreased from $69.3 \%$ to $61.7 \%$ of total energy (a relative decrease of $10.9 \%$ ) in the past 50 years. Shifts towards the Western diet are apparent among rural African dwellers as well. The South African Demographic and Health Survey conducted in 1998 revealed that $31.8 \%$ of African women (over the age of 15 years) were obese (body mass index $(\mathrm{BMI}) \geq 30 \mathrm{~kg} \mathrm{~m}^{-2}$ ) and that a further $26.7 \%$ were overweight (BMI $\geq 25$ to $<30 \mathrm{~kg} \mathrm{~m}^{-2}$ ). The obesity prevalence among men of the same age was $6.0 \%$, with $19.4 \%$ being overweight. The national prevalence of hypertension in blacks was $24.4 \%$, using the cut-off point of 140/90 $\mathrm{mmHg}$. There are limited data on the population's physical activity patterns. However, the effects of the HIV/AIDS epidemic will become increasingly important.

Conclusions: The increasing emergence of NCDs in black South Africans, compounded by the HIV/AIDS pandemic, presents a complex picture for health workers and policy makers. Increasing emphasis needs to be placed on healthy lifestyles.
\end{abstract}

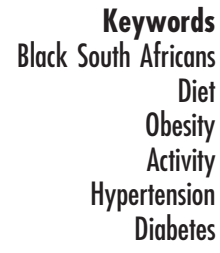

The black population in South Africa predominates over other population sub-groups (representing $77.4 \%$ of the population) ${ }^{1}$ and is the most impoverished of all groups. While the majority of blacks reside in 'non-urban' areas (56.7\%), the urban proportion (currently 43.3\%) is increasing steadily, with many living in informal housing on the fringes of cities. South Africa is suffering from a quadruple burden of disease - a combination of povertyrelated infectious disease, lifestyle-related non-communicable disease (NCD) and violence-related trauma. In addition, the HIV/AIDS epidemic is increasing rapidly. Modifiable risk factors that contribute to the development of NCDs in South Africa, such as obesity and inactivity, require much attention.

\section{The dietary transition in the black population of South Africa}

One of the hypotheses supported by rural/urban comparisons of African populations has been that the traditional diet is abandoned, with urban exposure, for a Western diet typified by decreases in carbohydrate and fibre and increases in fat. The traditional diet is associated with a low prevalence of degenerative diseases, whereas the Western diet is associated with increased prevalences $^{2,3}$.

Trends in African dietary data from the few available urban and rural studies are presented chronologically in Fig. $1^{4-14}$. The proportion of fat has increased and that of 


\section{Urban Studies}

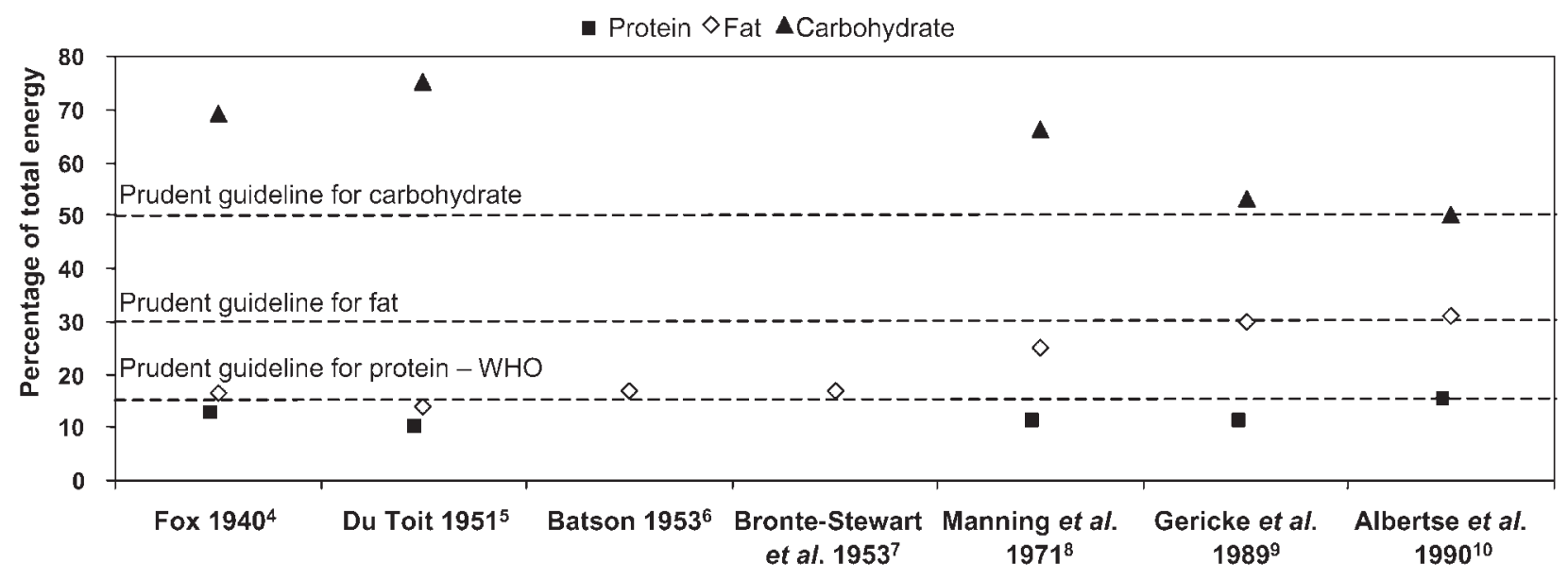

Rural Studies

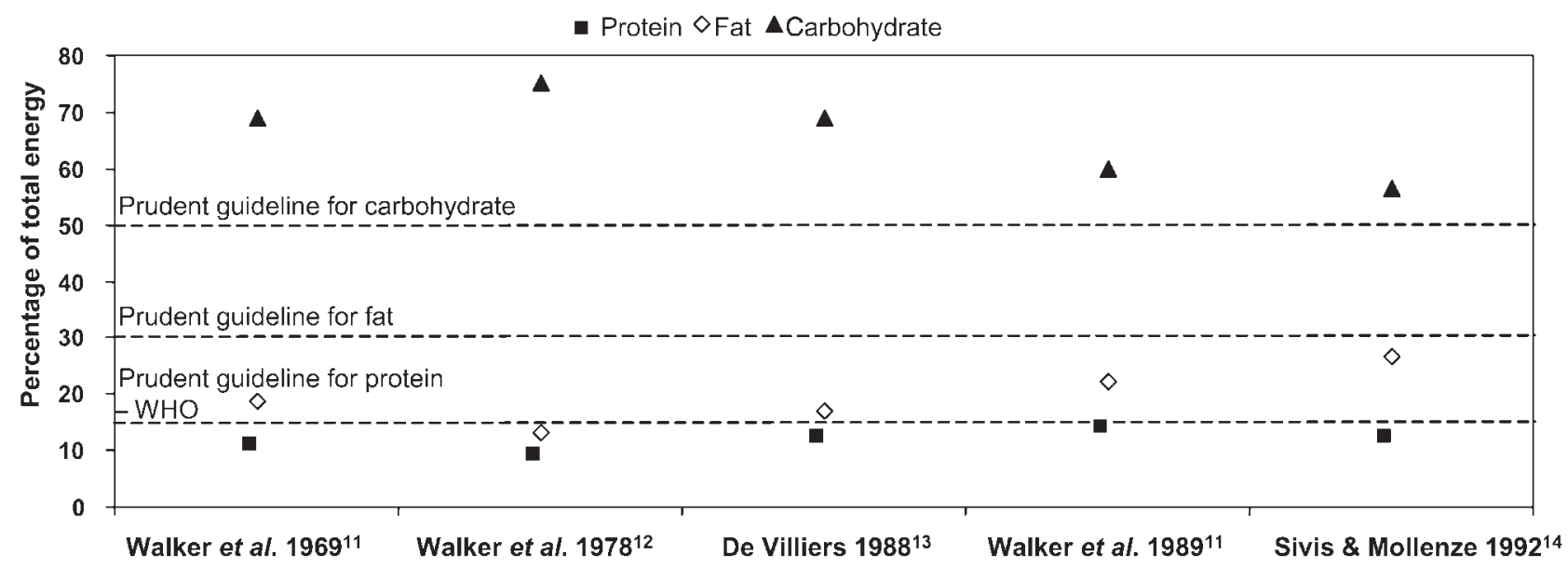

Fig. 1 Mean \% of energy from macronutrients among adult Africans in urban and rural areas of South Africa, illustrating changes in the structure of the diet, 1940-1990

carbohydrate has decreased in both rural and urban areas. The collective evidence of this data shows that although diets have met prudent dietary guidelines, there has been a shift over time towards the Western diet.

Manning et al. ${ }^{8}$ reported that such atherogenic changes were already evident in the Cape Peninsula blacks during the early 1970s, and Rossouw ${ }^{15}$ found 11-year-old urban black children of Cape Town to have higher levels of atherosclerotic risk factors than their rural counterparts. Since there was an absence of more recent dietary data of a representative sample of adult blacks in South Africa, a study was conducted in 1990 on a sample of 983 men and women, aged 15-64 years, in Cape Town. Years of urban exposure were determined from migration history and were used to calculate the percentage of each individual's life spent in a city. A breakdown of the macronutrient distribution stratified by urban exposure on a subset of adults, aged 19-44 years, revealed that reported fat intake (expressed as \% of energy) increased significantly
$(P<0.01)$, while carbohydrate intake decreased significantly $(P<0.01)^{16}$. Although significance was not reached for total protein, animal protein increased significantly $(P<0.01)$, while the \% of energy from plant protein decreased significantly $(P<0.01$, data not shown). Additionally, the Keys score $^{17}$ reflected a significant upward shift in dietary atherogenicity with increased urban exposure $(P<0.01)$. Hence, as urban exposure increased, so did the atherogenicity of the diet.

A comparison of fat and carbohydrate proportions of energy intake from these data, for adults aged 15-64 years, with that of black 'adults' (age range not provided) from the city of Johannesburg in $1940^{4}$ shows a relative $10.9 \%$ reduction of carbohydrate (from 69.3 to $61.7 \%$ of energy in 1990) ${ }^{16}$ and an increase of $59.7 \%$ in fat intake (from 16.4 to $26.2 \%$ of energy in 1990) ${ }^{16}$ over this 50-year period. Over this period, the absolute amounts of carbohydrate changed from 334 to $245 \mathrm{~g}_{\text {person }}{ }^{-1}$ day $^{-1}$ and that of fat from 34 to $54 \mathrm{~g}$ person ${ }^{-1} \mathrm{day}^{-1}$. These 
changes are more dramatic than have been observed in Western countries undergoing rapid industrialisation over longer periods of time.

Mean nutrient intakes of the Cape Town study are reported in detail elsewhere ${ }^{18}$. The results of the evaluation of macronutrient intake $(61.7 \%$ of energy from carbohydrate and $26.2 \%$ of energy from fat) revealed that the diet of this study population meets the requirements of the South African Diet Consensus Panel $^{19}$, which are in line with the American Heart Association's recommendations ${ }^{20}$. However, it represents a transitional phase between the 'traditional' diet $(>60 \%$ of energy from carbohydrate, $<25 \%$ of energy from fat) and a 'Western' eating pattern $(<50 \%$ of energy from carbohydrate, $>35 \%$ of energy from fats). Large percentages of individuals fell below two-thirds of the Recommended Dietary Allowance (RDA) ${ }^{21}$ for several vitamins and minerals, reflecting a nutritionally depleted diet.

An evaluation of the dietary patterns revealed diets confined to a relatively narrow range of foods ${ }^{22}$. Less than half the recommended ${ }^{23}$ two portions of milk per day were consumed. Furthermore, only about half the recommended minimum of four portions of fruits and vegetables was consumed by $50 \%$ of the population, with a quarter of respondents not reporting any. However, adequate intakes of cereals and components of the meat (two portions per day) and fat groups (3-8 teaspoons) were met. This pattern has also been found among other low-income population groups in South Africa as reflected in the South African Nutritional Status Survey (SANSS) report $^{24}$.

Further analyses ${ }^{25}$ of the Cape Town study revealed that the 'newer arrivals' to the city are associated with low educational status, informal housing and diets, and low atherogenicity, but with particularly low intakes of vitamins and minerals. In juxtaposition, the more urbanised individuals, with a higher educational status and living in formal housing, consumed diets somewhat richer in micronutrients, but with significantly higher atherogenicity. This suggests that improvements in socio-economic status do not necessarily lead to improved nutritional status, but are associated with a shift to another inappropriate nutritional pattern that predisposes to the development of atherosclerosis.

Many factors affect food choices and methods of food preparation. Poverty, lack of knowledge and social instability in the black population militate against healthy eating being a priority in the minds of township dwellers. The long commuting distances of employed city dwellers frequently result in choices of easy-to-prepare foods and snacks away from home, which are generally refined and high in fat content. Conversely, the more traditionally orientated individuals are frequently the under-employed 'newer arrivals', who may have the time to prepare relatively low-cost maize- and legume-based dishes, which have long cooking times. Dietary interventions have to consider these and other factors.

\section{Diet-related risk factors and non-communicable diseases in the South African black population}

Walker $^{26}$ predicted in 1972 that increasing urbanisation and a rise in socio-economic status in developing populations would increase their proneness to obesity, hypertension, diabetes and stroke. These predictions have largely been borne out in the African population.

\section{Obesity}

The early (pre-1950) anthropometric studies in African samples were either purely verbally descriptive (i.e. 'good', 'sturdy' or 'poor physiques') or used measures not comparable with those in use today. Moreover, the majority of studies were performed on mineworkers and children.

Data from three studies on adults in the 1990s ( $n>700$ each) reveal prevalences of obesity (BMI $\geq 30 \mathrm{~kg} \mathrm{~m}^{-2}$ ) in black women of $34.4 \% \%^{27}, 53.1 \%^{28}$ and $53.4 \%{ }^{28}$. These same studies found lower prevalences in men: $7.9 \%{ }^{27}$, $23.0 \%^{28}$ and $32.9 \%^{28}$, respectively. In the Cape Town study $^{27}$ the prevalence of overweight $(\mathrm{BMI}=24$ to $<30 \mathrm{~kg} \mathrm{~m}^{-2}$ ) for women was $36.4 \%$, and that for men $\left(\mathrm{BMI}=25\right.$ to $<30 \mathrm{~kg} \mathrm{~m}^{-2}$ ) was $22.0 \%$. Data for prevalences of overweight were not reported in either of the other two studies ${ }^{28}$.

The most recent data on obesity were collected during 1998 in the South African Demographic and Health Survey $(\mathrm{SADHS})^{29}$ that was conducted on a nationally representative sample of the population $(n=9903$ black men and women). Anthropometric measurements of men and women, aged 15 years or older, included weight and height as well as waist, hip and mid upper-arm circumferences. Summary data are presented for the black population in Table 1 .

These data show an adult South African population in which the pattern of malnutrition among adults is predominantly overnutrition rather than undernutrition, particularly in African women. This phenomenon was emphasised by the World Health Organization (WHO) for developing countries in $1997^{30}$. Obesity appears to start in these women at a young age, since the SADHS data reflect that $10 \%$ of women were obese at the age of $15-24$ years. Although the highest rates of obesity were reported among Africans, fewer than 5\% of the men and 15\% of the women perceived themselves to be obese.

In addition to the changes in nutritional patterns over time, and the degree of urbanisation that black South Africans are undergoing (described above), women with no education were found to have a lower mean BMI than those with schooling ${ }^{29}$. These women would tend to do more manual labour than their better-educated counterparts. 
Table 1 Anthropometric patterns of black South African adults, aged 15 to $65+$ years (age standardised against the world population) ${ }^{29}$

\begin{tabular}{lcc}
\hline Anthropometric pattern & Men $(n=4006)(\%)$ & Women $(n=5897)(\%)$ \\
\hline $\begin{array}{l}\text { Underweight } \\
\text { BMI }<18.5 \mathrm{~kg} \mathrm{~m}^{-2}\end{array}$ & 12.9 & 4.8 \\
$\begin{array}{l}\text { Normal weight } \\
\quad \mathrm{BMI} \geq 18.5 \text { to }<24.9 \mathrm{~kg} \mathrm{~m}^{-2}\end{array}$ & 61.7 & 36.7 \\
$\begin{array}{l}\text { Overweight } \\
\quad \mathrm{BMI} \geq 25.0 \text { to }<30 \mathrm{~kg} \mathrm{~m}^{-2}\end{array}$ & 19.4 & 26.7 \\
$\begin{array}{l}\text { Obese } \\
\quad \mathrm{BMI} \geq 30 \mathrm{~kg} \mathrm{~m}^{-2}\end{array}$ & 6.0 & 31.8 \\
$\begin{array}{l}\text { Mid upper-arm circumference } \\
\quad \geq 33.0 \mathrm{~cm}\end{array}$ & 10.2 & 30.6 \\
$\begin{array}{l}\text { Waist circumference } \\
\quad \text { Men, } \geq 102 \mathrm{~cm}^{30} \text { women, } \geq 88 \mathrm{~cm}\end{array}$ & 6.4 & 43.3 \\
$\begin{array}{l}\text { Waist/hip ratio } \\
\text { Men, } \geq 1.0 ; \text { women, }>0.85\end{array}$ & 6.9 & 35.2 \\
\hline
\end{tabular}

\section{Physical activity}

There are only a few regional, cross-sectional studies that have attempted to quantify physical activity patterns in representative samples of South Africans who are undergoing transition. In two large cross-sectional studies of risk factors in urban black communities in the Western Cape province, $30-40 \%$ of men and women reported being inactive or minimally active in their work or leisure time $^{31,32}$. Groups at greatest risk for low levels of physical activity in urban and peri-urban communities include young women who left school (15-24 years) and older men and women over the age of 55 years. Furthermore, in a sample $(n=980)$ from a peri-urban community of the Western Cape, lack of physical activity was a significant risk factor for non-insulin-dependent diabetes mellitus $\left(\right.$ NIDDM) $(\text { relative risk }(\mathrm{RR})=1.67)^{33}$. Recently, a survey conducted on transitional African communities in the Northwest Province of South Africa ${ }^{34}$ demonstrated that inactivity, independent of the degree of urbanisation, was associated with increasing obesity level $(P=0.0007)$.

In terms of physical activity and health promotion, initiatives in South Africa have been fragmented, with little or no intersectoral collaboration. This may in part be attributed to:

1. emphasis within the formal health sector on primary health care delivery in lieu of preventative measures;

2. collapse of physical education within public schools and the historical absence of such programmes in disadvantaged communities;

3. lack of basic infrastructure for exercising in many periurban and urban communities; and

4. high prevalence of urban violence and risk to personal safety.

There are, unfortunately, few examples of sustainable programmes for group physical activity participation. However, one such example is the Community Health Intervention Programme (CHIPs) - a joint venture between a privately funded, non-profit organisation and a national insurance company. This programme works with a range of community bodies - from civic associations, church groups, seniors clubs and children's homes, to universities and teaching colleges. The aim is to enable previously disadvantaged communities to begin health promotion projects using physical activity as the vehicle. Separate programmes target children, adults and older adults. The ultimate aim is to implement a working model of broader participation in physical activity nation-wide.

The effectiveness of low-intensity exercise for older adults from the CHIPs communities in the Western Cape province was measured $^{35}$ in a small, community-based, randomised controlled trial. Exercise training was associated with (1) improved dynamic balance, measured by the time taken to walk 10 metres using a tandem gait $(P<$ 0.001 ), and (2) lower body strength, measured by the number of sit-to-stand repetitions completed in a 10 -second period $(P<0.001)$. Most importantly, systolic blood pressure decreased by an average of $4 \mathrm{mmHg}(P<$ $0.009)$ in exercising groups after 20 weeks, compared with no change in the control group. This occurred without a change in weight or body composition. These results suggest that a simple community-based programme run by peer group leaders, of twice weekly low-intensity exercise, may be sufficient to significantly lower systolic blood pressure, thus lowering the burden of disease in this 'at risk' population.

\section{Hypertension}

The national prevalence rate of $21 \%^{36}$, using the WHO/International Society of Hypertension (ISH) definition $^{37}$, is equivalent to that in other industrialised countries $^{38}$ and greater than that of many developing countries $^{39}$. It is likely that the prevalence rates will increase with time in the African population (total prevalence, 24.4\%; men, 23.5\%; women, $25.0 \%$ ) now rapidly adopting Western lifestyle habits.

\section{Diabetes}

When the traditional lifestyle among blacks was followed in the past, diabetes was virtually absent, as it still is in rural 
Tanzania ${ }^{40}$. Early studies in South Africa, dating from 1960, to determine the prevalence of diabetes were entirely hospital-based. However, in a 1969 population-based study in Cape Town, the crude prevalence was $3 \%{ }^{41}$.

More recent community-based studies using the 1985 WHO criteria for diabetes indicate that the prevalence is considerably higher in African subjects than approximately 25 years ago, ranging from 5\% in Gauteng ${ }^{42}$ to $8.0 \%$ in Cape Town ${ }^{32}$. However, the true extent of this change may be confounded by differences in methodology.

Importantly, the Cape Town survey ${ }^{32}$ identified the following as independent risk factors: age, upper segment body fat distribution, urbanisation (i.e. more than $40 \%$ of life spent in an urban area) and obesity.

\section{Conclusions}

South Africa needs to deal with the increasing onset of chronic diseases of lifestyle, while there is still an unfinished process of reducing infections and violencerelated trauma. Superimposed on these is the HIV/AIDS epidemic (with $26 \%$ of women of reproductive age already infected), which is rapidly gaining momentum to become the most important cause of morbidity and mortality. Resource allocation between these competing demands poses extremely difficult public health policy options. However, it is clear that far more intensive efforts are required in the promotion of healthy lifestyles.

\section{References}

1 Statistics South Africa. Population Census, 1996: Primary Tables. Report 03-01-17 (1996). Pretoria: Statistics South Africa, 1999.

2 Burkitt DP. Western diseases and their emergence related to diet. S. Afr. Med. J. 1982; 61: 1013-5.

3 Segal I, Walker ARP. Low fat intake with falling fibre intake commensurate with rarity of non-infective bowel diseases in blacks in Soweto, Johannesburg, South Africa. Nutr. Cancer 1986; 8: 185-91.

4 Fox FW. Diet in the urban locations as indicated by the survey. In: Janisch M, ed. A Study of African Income and Expenditure in 987 Families in Johannesburg. City of Johannesburg: Department of Non-European and Native Affairs, 1940.

5 Du Toit B. Dietary survey amongst 100 native families in the Payneville Location, Springs. S. Afr. J. Soc. Sci. 1951; 4: $63-73$.

6 Batson E. The ethnic differentiation of fat-calorie ratios in household food purchases in Cape Town. J. Soc. Res. 1953; 4: $113-5$.

7 Bronte-Stewart B, Keys A, Brock JF. Serum cholesterol, diet and coronary heart disease. Lancet 1953 ; ii: $1103-8$.

8 Manning EB, Mann JI, Sophangisa E, Truswell AS. Dietary patterns in urbanised blacks. S. Afr. Med.J. 1971; 48: 488-98

9 Gericke GJ, Loock ME, Marzner L, van der Merwe CA. Die macronutrientinname en serumlipiedwaardes van swartes met en sonder IHS. J. Diet Home Econ. 1989; 17: 41-6.

10 Albertse EC, Neethling A, de Villiers MA. Diet and lifestyle differences between rural and urban Zulu women. S. Afr. J. Food Sci. Nutr. 1990; 2(Suppl. 1.1): 1.

11 Walker ARP, Walker BF, Walker AJ. Comparison of nutrient intakes of South African elderly black women in 1969 and 1989. J. Hum. Nutr. Diet. 1992; 5: 169-77.

12 Walker ARP, Walker BF. High high-density lipoprotein cholesterol in African children and adults in a population free of coronary heart disease. BMJ 1978; 2: 1336-8.

13 De Villiers MA. Diet, lifestyle and the prevalence of obesity and hypertension among Zulu women in a remote rural area. MSc thesis, University of Stellenbosch, South Africa, 1988.

14 Sivis N, Mollenze WF. Nutrient intakes of black inhabitants in Qwa Qwa and Bloemfontein. Unpublished, University of Potchefstroom, 1992.

15 Rossouw LJ. An interracial comparison of atherosclerosis precursors in 11-year-old South African children. MSc thesis, University of Stellenbosch, South Africa, 1990.

16 Bourne LT. Dietary intake in an urban African population in South Africa - with special reference to the nutrition transition. PhD thesis, University of Cape Town, South Africa, 1996.

17 Shekelle RB, Shyrock A, Mac M, Paul O. Diet and serum cholesterol and death from coronary heart disease: The Western Electric Study. N. Engl. J. Med. 1981; 304: 65-70.

18 Bourne LT, Langenhoven ML, Steyn K, Jooste PL, Laubscher JA, Van der Vyfer E. Nutrient intake in the urban African population of the Cape Peninsula, South Africa. The BRISK study. Cent. Afr. J. Med. 1993; 39: 238-347.

19 Diet Consensus Panel. Dietary recommendations for the prevention of coronary heart disease. S. Afr. Med.J. 1989; 76: $591-2$.

20 American Heart Association. Dietary guidelines for healthy American adults. Position Statement. Circulation 1988; 77: $721 \mathrm{~A}-4 \mathrm{~A}$.

21 Food and Nutrition Board, US National Research Council. Recommended Dietary Allowances, 10th ed. Washington, DC: National Academy Press, 1990.

22 Bourne LT, Langenhoven ML, Steyn K, Jooste PL, Nesamvuni $\mathrm{AE}$, Laubscher JA. The food and meal pattern in the urban African population of the Cape Peninsula. The BRISK study. Cent. Afr. J. Med. 1994; 40: 140-8.

23 Department of Health Services and Welfare, Administration: House of Assembly. Guide to Healthy Eating. Pretoria: Promedia, 1990.

24 Vorster HH, Jerling JC, Oosthuizen W, Becker P, Wolmarans P. Nutrient Intakes of South Africans: An Analysis of the Literature. SANSS Group Report to Roche Products, Potchefstroom, 1995; 41

25 Steyn K, Katzenellenbogen J, Lombard CJ, Bourne LT Urbanisation and the risk for chronic diseases of lifestyle in the black population of the Cape Peninsula, South Africa. J. Cardiovasc. Risk 1997; 4: 135-42.

26 Walker ARP. Urbanisation of developing populations: bearing of rise in privilege and the prevalence of diseases of nutritional deficiency and excess. In: Chaves A, Bourges $\mathrm{H}$, Basta S, eds. Proceedings of the 9th International Congress on Nutrition, Mexico. Basel: Karger, 1972; 26-31.

27 Steyn K, Bourne LT, Jooste PL, Fourie J, Rossouw K, Lombard C. Anthropometric profile of a black population of the Cape Peninsula in South Africa. East Afr. Med.J. 1998; 75: 35-40.

28 Mollentze WF, Moore AJ, Steyn AF, Joubert G, Steyn K, Oosthuizen GM. Coronary heart disease risk factors in a rural and urban Orange Free State population. S. Afr. Med.J. 1995; 85: $90-6$.

29 Puoane T, Steyn K, Bradshaw D, Lambert EV, Fourie J, Laubscher JA. Anthropometry and obesity in South Africa the National Demographic and Health Survey, 1998. Int. $J$. Obes. [in press]. Personal correspondence.

30 World Health Organization (WHO). Obesity: Preventing and Managing the Global Epidemic. Report of a WHO Consultation on Obesity, Geneva: WHO, 3-5 June 1997.

31 Steyn K, Jooste PL, Bourne L, Fourie JM, Badenhorst CJ, 
Bourne DE. Risk factors for coronary heart disease in the black population of the Cape Peninsula. S. Afr. Med.J. 1991; 79: 480-5.

32 Levitt NS, Katzenellenbogen JM, Bradshaw D, Hoffman MN, Bonnici $F$. The prevalence and risk factors for NIDDM in urban Africans in Cape Town, South Africa. Diabetes Care 1993; 16: 601-7.

33 Levitt NS, Steyn K, Lambert EV, Fourie JM, Rossouw K. Modifiable risk factors for Type 1 diabetes mellitus in a periurban community in South Africa. Diabet. Med. 1999; 16: $1-5$.

34 Kruger HS, Venter CS, Vorster HH, et al. Physical inactivity is an important contributing factor to obesity in black women in the North West. S. Afr. Med.J. 1999; 89(4): 463.

35 Kolbe TL, Lambert EV, Charlton K, Noakes TD. Effectiveness of a low intensity, community-based exercise program for older South Africans from previously disadvantaged communities. Med. Sci. Sports Exerc. 1999; 31(Suppl. 5): S185.

36 Steyn K, Gaziano TA, Bradshaw D, Laubscher JA. Hypertension in South African adults: results from the Demographic and Health Survey. J. Hypertens. [in press].

37 Guidelines Subcommittee 1999. World Health Organisation/
International Society of Hypertension guidelines for management of hypertension. J. Hypertens. 1999; 17: 151-83.

38 Burt VL, Whelton P, Rocella EJ, Brown C, Cutler JA, Higgins M. Prevalence of hypertension in the US adult population. Results from the Third National Health and Nutrition Examination Survey, 1988-1991. Hypertension 1995; 25: 305-13.

39 Fuentes R, Illmaniemi N, Laurikainen E, Tuomilehto J, Nissinen A. Hypertension in developing economies: a review of population based studies carried out from 19801988. J. Hypertens. 2000; 18: 521-9.

40 McLarty DG, Pollitt C, Swai ABM. Diabetes in South Africa. Diabet. Med. 1990; 7: 670-84.

41 Goldberg MD, Marine N, Ribeiro F. Prevalence of glycosuria and diabetes among Indians and Bantu. S. Afr. Med. J. 1969; 43: 733-8.

42 Omar MAK, Seedat MA, Motala AA, Dyer RB, Becker P. The prevalence of diabetes mellitus and impaired glucose tolerance in a group of urban South African blacks. S. Afr. Med. J. 1993; 83: 641-3. 